https://www.journal-imab-bg.org

Original article

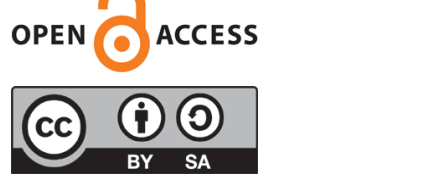

\title{
ANALYSIS OF USAGE AND QUALITY OF WILD EDIBLE MUSHROOMS BY PEOPLE FROM BULGARIA, COMPARED TO OTHER FOREIGN COUNTRIES
}

\author{
Tsonka Dimitrova ${ }^{1}$, Petko Marinov ${ }^{2}$, Galina Yaneva ${ }^{1}$, Dobri Ivanov ${ }^{1}$ \\ 1) Department Biology, Faculty Pharmacy, Medical University, Varna, Bulgaria \\ 2) Department Pharmacology, Toxicology and Pharmacotherapy, Faculty Phar- \\ macy, Medical University, Varna, Bulgaria.
}

\begin{abstract}
Purpose: Wild edible mushrooms are collected and consumed for centuries worldwide and in Bulgaria as well. This questionnaire investigation aimed at assessing some common mushroom usage practices in a random sample from the population in Varna region, Bulgaria.

Material/Methods: We performed a study of 200 adult individuals, 100 males and 100 females, from Varna region using anonymous questionnaire with 12 basic items about wild edible mushroom usage. Statistical data processing was performed using descriptive methods and correlation analysis.

Results: There was a prevalence of male and female individuals with secondary and higher education. Most respondents preferred wild edible mushroom gathering in contrast to purchasing. The positive attitude towards wild edible mushroom usage as food is more common in males than in females. Most respondents consumed wild edible mushroom several times during any year. There were statistically significant correlations between urban main residence, on one hand, and wild edible mushroom non-nutritional usage, cooking, drying, preservation and freezing, on the other hand; between secondary educational level, on one hand, and positive attitude towards nutritional usage of wild edible mushrooms, wild edible mushroom cooking, preservation, freezing and drying and applications as therapeutic means; as well as between individual female sex belonging and wild edible mushroom applications as therapeutic means, on the other hand.

Conclusion: This questionnaire investigation revealed several interesting peculiarities of the attitudes towards wild edible mushrooms among the population of Varna region and the extent of usage of common mushrooms depending on sex, educational level and main residence of respondents.
\end{abstract}

Keywords: wild edible mushrooms, usage, inquiry, region of Varna,

\section{INTRODUCTION}

Wild edible mushrooms have been collected and consumed by human populations for centuries, and today they represent a relevant source of food and income for many rural families worldwide [1]. The recent literature related to lactic fermentation use in the process of preservation of edible mushroom fruiting bodies is comprehensively reviewed [2]. Particular attention is paid to the aspects of the technological process and its impact on the quality and potential suitability of the final products.

The innovations and nutraceutical benefits of mushrooms, as well as the practices of their cultivation, processing equipment, methods of preservation and value-added based products are summarized in a review of recent investigations and patents [3]. The mushrooms are processed into various products to increase their consumption, thus providing health and nutritional benefit to mankind.

To take examples from other nations in Europe, it is worth mentioning, that during the twentieth century, the Swedish urban middle class consumes mushrooms as basic food and is closely followed by the working-class people, and the chanterelle mushroom, Cantharellus cibarius Fr., is the most popular species for both population groups [4]. During the last 100 to 140 years, Sweden people had changed from a mycophobic to a mycophilic society with a passionate interest in the utilization of wild mushrooms. The so-called hipster-generation, born in the 1990s, harvested mushrooms due to the interest in producing their own food and often used social media to identify edible species. In the early years of the twenty-first century, mushrooming has also become a thriving pastime among people with an urban lifestyle.

How and what could be Bulgaria and the Balkans, as another region in Europe, in terms of mushroom usage for often meal, is also a question to reveal.

The objective of our questionnaire investigation was to assess some common usage practices of wild edible mushrooms within a random sample from the population in Varna region, Bulgaria. 


\section{MATERIALS \& METHODS}

We performed in 2020 a study of 200 adult individuals, 100 males and 100 females, from Varna region, using anonymous questionnaire, addressed to their attitude to wild edible mushroom usage. The respondents were asked to express their own opinion concerning a total of 12 definite items about methods of gathering, preparation and consumption of wild edible mushrooms, available in towns and villages of Varna region.

The distributions of all respondents according to sex and age groups, education and basic residence are demonstrated on Fig. 1, through Fig. 3.

Fig. 1. Distribution of respondents according to sex and age groups

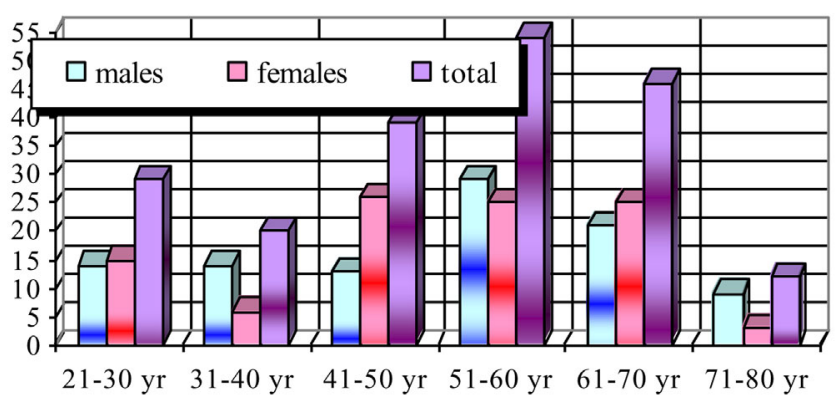

Fig. 2. Distribution of respondents according to sex and education

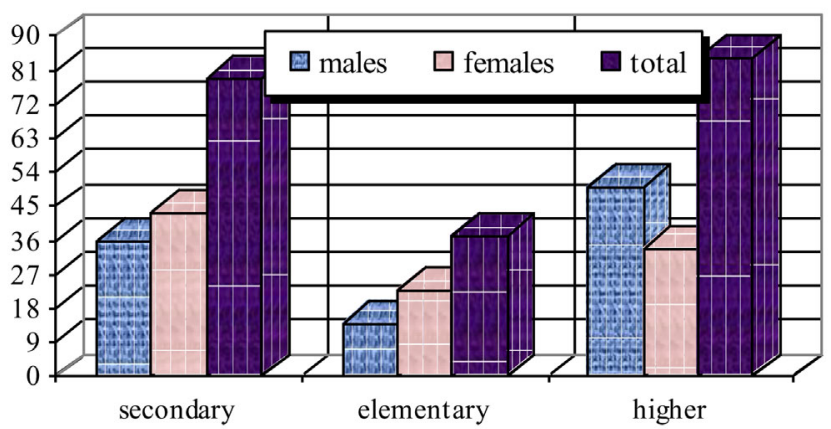

Fig. 3. Distribution of respondents according to sex and basic residence

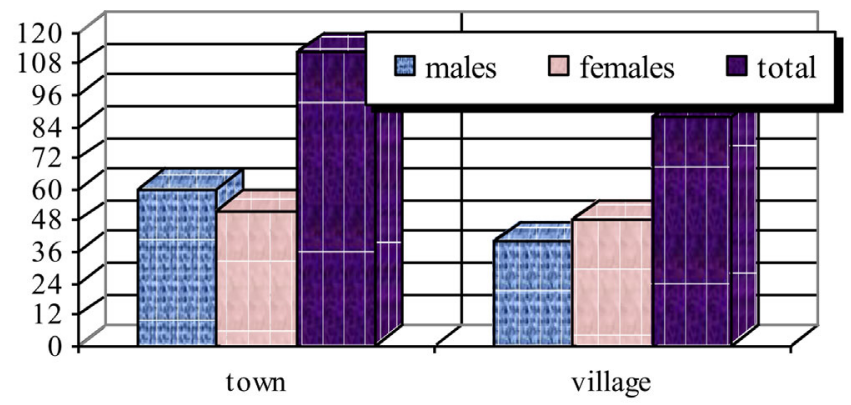

Statistical data processing was performed using descriptive methods and correlation analysis (Pearson's coefficient, $\chi^{2}$ independent test and Fisher's exact test). Statistical significance was considered at level of $\mathrm{p}<0.05$.
There is a slight prevalence of male respondents with higher education, as well as of female respondents with secondary and with elementary education. There is a slight prevalence of male respondents from urban districts, as well as of female respondents from rural regions.

\section{RESULTS}

Our initial results are presented in four tables and three figures.

As shown in Table 1, most male and female respondents prefer wild edible mushroom gathering towards purchasing. Next comes the acquisition from acquaintants and their knowledge for mushrooms.

Table 1. Distribution of respondents according to sex and manner of edible mushroom acquisition

\begin{tabular}{|l|c|c|c|}
\hline Manner of acquisition & males & females & total \\
\hline gathering & 60 & 45 & 105 \\
\hline from acquaintances & 45 & 37 & 82 \\
\hline purchasing & 28 & 19 & 47 \\
\hline
\end{tabular}

The attitude towards the usage of the wild edible mushroom as food is illustrated in Fig. 4.

The positive attitude of male and female respondents considerably dominates over the negative and lacking usage.

Fig. 4. Distribution of respondents according to sex and attitude towards wild edible mushroom usage

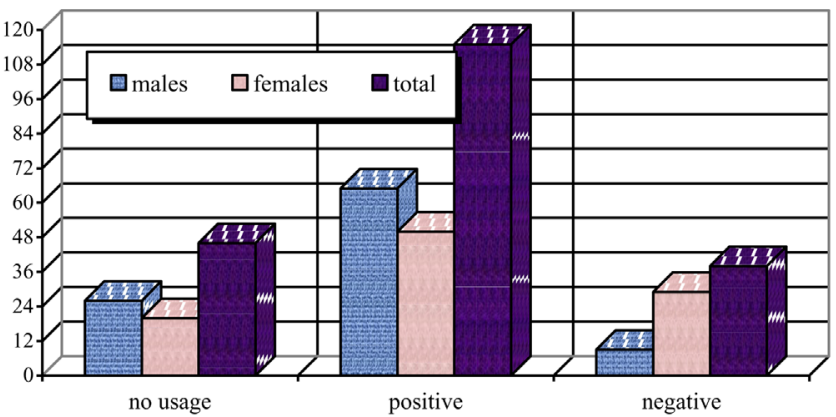

The positive attitude of male and female respondents towards wild edible mushroom usage as food considerably dominates over the negative and lacking usage. This positive attitude is more common in males than in females. There is statistically significant correlation dependence between male sex and this attitude (Pearson's coefficient $\left.\chi^{2}=13.261 ; \mathrm{p}<0.001\right) . \quad$ Distribution of respondents according to sex and edible mushroom non-nutritional usage is illustrated in Fig. 5.

As a whole, the attitude of males, but also of females, towards usage of wild edible mushrooms, rather than food, is negative. 
Fig. 5. Distribution of respondents according to sex and edible mushroom non-nutritional usage

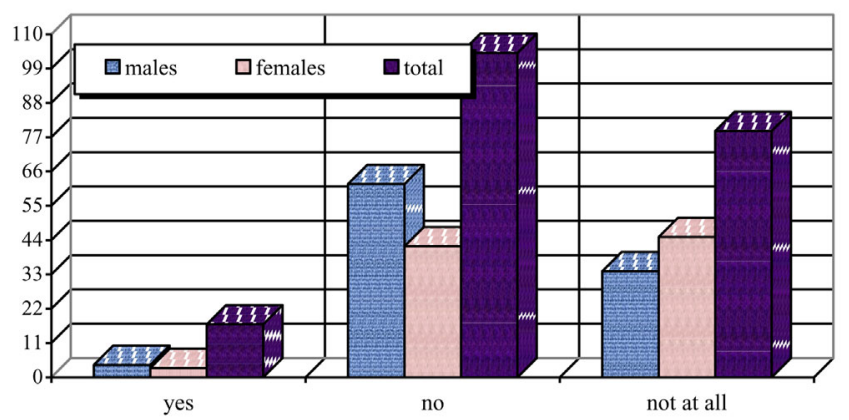

Distribution of respondents according to sex and manner of edible mushroom preparation is demonstrated in Table 2.

Cooking is the most preferred preparation option by males and females followed by preservation. It is interesting that mushroom drying is very rarely introduced and recommended by all respondents.

Table 2. Distribution of respondents according to sex and manner of edible mushroom preparation

\begin{tabular}{|l|c|c|c|}
\hline Manner of preparation & males & females & total \\
\hline cooking & 65 & 53 & 118 \\
\hline preserving & 42 & 39 & 81 \\
\hline drying & 32 & 22 & 54 \\
\hline freezing & 10 & 14 & 24 \\
\hline
\end{tabular}

In addition, there are statistically significant correlation dependences between urban town residence, on one hand, and wild edible mushroom non-nutritional usage (Pearson's coefficient $\chi^{2}=18.554 ; \mathrm{p}<0.0001$ ), wild edible mushroom cooking (Pearson's coefficient $\chi 2=21.690$; $\mathrm{p}<0.0001$; Fisher's exact test $\mathrm{p}<0.0001$ ), wild edible mushroom drying (Pearson's coefficient $\chi^{2}=18.048$; $\mathrm{p}<0.0001$; Fisher's exact test $\mathrm{p}<0.0001$ ), wild edible mushroom preservation (Pearson's coefficient $\chi^{2}=4.562 ; \mathrm{p}=0.033$; Fisher's exact test $\mathrm{p}<0.023)$ and wild edible mushroom freezing (Pearson's coefficient $\chi^{2}=10.637 ; \mathrm{p}=0.001$; Fisher's exact test $\mathrm{p}<0.001)$ as well, on the other hand.

There are statistically significant correlations between secondary educational level, on one hand, and positive attitude towards nutritional usage of wild edible mushrooms (Pearson's coefficient $\chi^{2}=28.795$; $p<0.0001$ ), wild edible mushroom cooking (Pearson's coefficient $\chi^{2}=26.864 ; \mathrm{p}<0.0001$ ), wild edible mushroom preservation (Pearson's coefficient $\chi^{2}=15.185 ; \mathrm{p}<0.001$ ), wild edible mushroom freezing (Pearson's coefficient $\chi^{2}=13.628$; $\mathrm{p}<0.001$ ), wild edible mushroom drying (Pearson's coefficient $\chi^{2}=8.800 ; \mathrm{p}=0.012$ ) and wild edible mushroom applications as therapeutic means (Pearson's coefficient $\left.\chi^{2}=8.310 ; \mathrm{p}<0.016\right)$, on the other hand.

We establish a statistically significant correlation between individual female sex belonging and wild edible mushroom applications as therapeutic means (Pearson's co- efficient $\chi^{2}=7.680 ; p<0.006$; Fisher's exact test $\mathrm{p}<0.05$ ), as well.

Fig. 6 clearly indicates that most respondents, mainly males, consume wild edible mushroom several times during a year. The number of the respondents in terms of females, who do not consume mushrooms at all, is, however, significant.

Fig. 6. Distribution of respondents according to sex and annual edible mushroom consumption

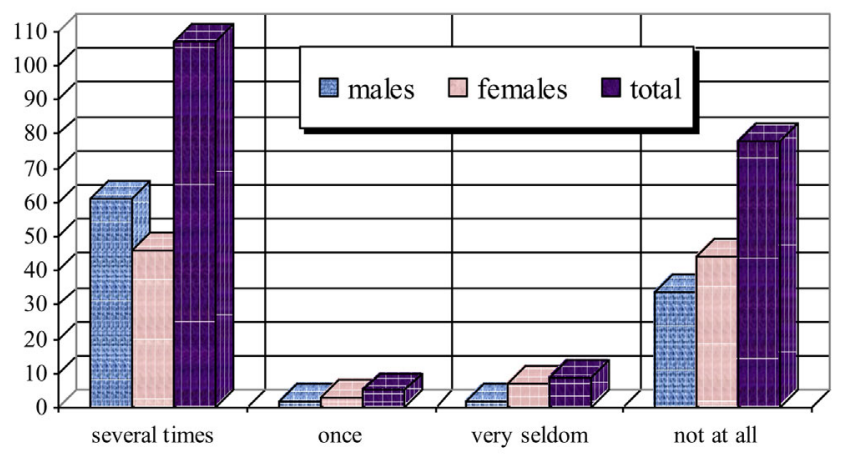

Distribution of respondents according to sex, as well as in terms of trade and seasonal gathering of wild edible mushroom is presented in Table 3 and Table 4.

Table 3. Distribution of respondents according to sex and edible mushroom trading

\begin{tabular}{|l|c|c|c|}
\hline Mushroom trading & males & females & total \\
\hline gathering for selling & 60 & 42 & 102 \\
\hline purchasing from stations & 33 & 22 & 55 \\
\hline delivering to stations & 17 & 10 & 27 \\
\hline
\end{tabular}

The respondents prefer gathering for selling of wild edible mushrooms, in contrast to delivery to specialized stations, which is a relatively seldom practice.

Table 4. Distribution of respondents according to sex and edible mushroom seasonal gathering

\begin{tabular}{|l|c|c|c|}
\hline Seasonal gathering & males & females & total \\
\hline in Spring & 59 & 44 & 103 \\
\hline in Autumn & 42 & 26 & 68 \\
\hline in Summer & 4 & 8 & 12 \\
\hline
\end{tabular}

Gathering of the wild edible mushrooms by males and females in Spring is very common while gathering in Summer is very rare, especially by males.

\section{DISCUSSION}

Our present results are similar to data published recently in the available foreign literature.

We establish moderate differences between male and female respondents in terms of age, educational level and basic residence. 
The analysis of the recent literature convincingly proves the increasing importance of different sociological methods, which are applied alone or within purposeful ethnomycological investigations.

During the past 40 years, ethnomycological information about gathering and use of wild mushrooms in the Upper Sangone Valley, Western Italian Alps, Piedmont, North Western Italy, is obtained through 47 in-depth open and semi-structured interviews with community members [5]. Recently, the collection of mushroom genera growing in more anthropogenic environments or possibly promoted via popular books and media has been introduced.

The ethnomycological study of the population in Menge District, Asossa Zone, Benshangul Gumuz Region, Ethiopia, using semi-structured interviews, focus group discussions, participant observations and walk-in-thewoods methods identifies 15 wild edible mushroom species [6]. Their collection habit and practice is statistically significantly influenced by gender, age, and literacy level $(\mathrm{p}<0.05)$.

The ethnomycological investigation of 160 inhabitants in six different ethnic communities from the Tshopo province in the Democratic Republic of the Congo indicates that these people use 73 species of wild edible mushrooms either for food (68 species), as medicine (nine species), in a recreational context (two species), or related to myths and beliefs (seven species) [8]. Women are more involved in harvesting and are the main holders of cultural aspects related to mushrooms. Pleurotus tuber-regium is the most important species that is used mainly for food and a medicine. Some mushroom pickers deliberately cut down host trees to promote the development of saprotrophic taxa.

The results from the ethnobiological study of rural inhabitants of five Mapuche communities from North Western Patagonia, Argentina, demonstrate that community members consume mushrooms fresh in situ, after some processing, or stored for later consumption, or trade [7]. Most wild edible mushrooms have commercial value, continuous usage over time, and outstanding organoleptic properties. There are different practices, transferences, resignifications, and new technologies for storage.

Pleurotus species are predominantly found in tropical forests and often grow on fallen branches, dead and decaying tree stumps. They are commercially essential mushrooms and widely cultivated throughout the world. In Korea, their cultivation is economically profitable, and it is one of the highly consumed species [9]. Pleurotus mushrooms find unique applications as flavouring, aroma, and excellent preservation quality and have a unique status delicacy with high nutritional and medicinal values. Their cultivation is an ecology-friendly process for converting various agricultural wastes into human food. Besides it is most suitable and profitable in three climatic world areas, i.e. tropical, subtropical, and temperate regions.

The results from an investigation in areas regularly used, or not, for mushroom harvesting in the Mixteca region of Oaxaca, Mexico, indicate that intensive harvest- ing of wild edible mushrooms does not affect the diversity and distribution of macrofungal species [1].

A total 748 respondents belonging to 13 ethnic groups in the main and highest protected areas of Côte d'Ivoire are interviewed about uses of wild edible mushrooms [10]. Sixty-eight useful wild fungal species belonging to 17 families and 23 genera are listed and collected. Rural people report four categories of usage such as food, medicinal, belief and recreational as food (56 species) and medicinal (16 species) uses dominate. Such usage varies not only between sociolinguistic groups, but also between visited villages. The most commonly used mushrooms are Auricularia spp., Psathyrella tuberculata and Termitomyces spp.

Gathering for selling of wild edible mushrooms is the main manner of trading and Spring is the preferred season for this activity of the respondents in our study.

The traditional usages and relevant selling practices of edible wild mushrooms by Maya inhabitants of the municipality of San Juan Sacatepéquez in Kaqchikel area in the central highlands of Guatemala are assessed and the diversity and composition of the mushroom assemblage, offered at the market with the macrofungal diversity of woods in this area, are compared by means of focused interviews with collectors and vendors [11]. There is a significant richness of species sold in the market, a network of commerce of purchase, sale, and resale of several species, with relatively stable prices. Selling mushrooms business in the market is an exclusive activity of women supplied by collectors or by other vendors. Fungi are sold and bought only as food. Recently, several species of Amanita, Cantharellus, Boletus, Lactarius, and Russula are most commercialized.

In a case study, traditional knowledge systems about artisanal mycoculture are addressed to identify locally used substrates for indigenous cultivation practices of six wild saprophytic mushroom species that enhance sustainable utilization of natural resources across five districts in Uganda using focus groups and semi-structured interviews [12]. The management practices and substrates used for each species differ according to the mushroom's mode of decomposition.

The cultural, economic, ecological aspects and management techniques of wild mushrooms interchanged in three traditional markets of the Pátzcuaro Lake region, Central-Western Mexico are documented within 175 visits to markets and 89 semi-structured interviews to producers, gatherers and sellers [13]. There are 17 species of edible mushrooms. Gathering and silvicultural management (in situ management in forests) are practiced in all mushrooms from forests and agricultural areas. All mushroom species offered to the markets are gathered in forests without any other management form.

Between 2009 and 2014, 116 non-structured and semi-structured interviews were performed to analyze the cultural significance and use of wild mushrooms in communities of the Mixteca Alta, Southeastern Mexico, focusing on the usage of the identified species [14]. There is a complex and accurate awareness of Mixtecs related 
to wild mushroom use. A relation between such usage and natural vegetation cover, lower soil erosion, higher economic marginalization and richness in these communities is proved.

During ethnobiological tours, semi-structured interviews with 37 individuals from different communities in the municipality of Villa Guerrero in Northern Jalisco, Mexico, about edible mushrooms were carried out [15]. Traditional use of mushrooms and related practices is assessed. There are records of 37 mushroom species with edible, medicinal, and recreational uses. Some toxic mushrooms are associated with the divine, as evidenced by one case of their use, as a hierophanic agent. There is a loss in practices concerning mushrooms as a result of social changes. Some mushrooms, especially Volvariella bombycina and Pleurotus djamor, are preferred to other foods, including meat.

We find out that cooking is most commonly used for home preparation of wild edible mushrooms by our respondents of both sexes.

Between 2010 and 2012, semi-structured interviews of 197 habitants in seven locations in Urique, Bocoyna, and the Cusarare area within two municipalities of the $\mathrm{Si}$ erra Tarahumara, Chihuahua, Northern Mexico, concerning the use of edible mushrooms are carried out [16]. Peculiarities of local species consumed, preparation methods, forms of preservation, economic aspects and other uses such as home decorations, medicine or as food in breeding rams are examined.

The analysis of a total of 695 semi-structured interviews about traditional use of wild edible mushrooms among local informants in Mazovia, Poland, identifies 92 taxa, of which 76 species are used as food, 21 taxa known as toxic, and 11 taxa used for non-culinary purposes [17]. The mean number of edible taxa mentioned per interview is 9.5. Frequent interaction with mushroom collectors enables the transcription of local folk taxonomy into proper taxonomic classification and the definition of changes in local preferences concerning wild edible mushroom collection.

Three main traditional markets of the Phurépecha region of Michoacán, Mexico, are studied through 140 visits to markets and 60 semi-structured interviews to sellers of wild mushrooms [18]. There are 15 mushroom species offered to the markets. The highest cultural values are identified in multipurpose mushroom resources. In markets, women are the main actors and associates of the regional household activities of use and management of local resources and ecosystems. Most mushrooms are obtained by simple gathering although they have high demand and value in the markets. These markets influence on social relations, cultural identity and preservation of traditional knowledge and biodiversity.
In our study, there is a dominating positive attitude of respondents towards wild edible mushroom nutritional usage.

The use of wild mushrooms for food and medicine in three rural areas of Sweden, Ukraine and the Russian Federation is studied by means of a total of 205 in-depth semi-structured interviews [19]. These regions are the following: Småland (South Sweden), Roztochya (Western Ukraine) and Kortkeros (Komi Republic in North West Russia). Most respondents in Småland and all respondents in Roztochya and Kortkeros collect wild mushrooms. In Småland, some respondents prepare preserves from mushrooms for personal consumption during winter times. Chanterelles are frozen and consumed during winter time and funnel chanterelle are used dried for stews and sauces while most respondents collect chanterelle and funnel chanterelle once or twice per year for immediate cooking. In Ukraine and Russia, Boletus species are dried or marinated (pickled) and considered a delicacy. Armillaria spp. is mainly used marinated while Russula spp. is used only fresh for immediate cooking. Due to availability of deepfreezers in Ukraine and Russia, deep-frozen mushrooms are recently preferred over marinating as a preservation technique for winter times. In Russia, Lactarius spp. is most commonly salted and pickled. It is a delicacy and a part of rural cuisine for centuries. In those economically less developed rural areas of Ukraine and Russia, wild mushrooms continue to be an important part of livelihoods, as a source of income and for domestic use, as food and medicine, while in Sweden, their collection has become mainly a recreational activity [19].

Local use of wild edible mushrooms among 121 permanent residents in six localities of the Bamenda Highlands of Cameroon, 76 males and 45 females aged up to 50 years, is documented by means of interviews and field observations [20]. Some $32 \%$ of the indigenous respondents regularly consume these mushrooms. In their opinion, excessive collection and other human activities including overgrazing, agricultural land expansion and uncontrolled bushfires are the main reasons for wild edible mushroom scarcity.

\section{CONCLUSION}

Our questionnaire investigation reveals some interesting peculiarities of the attitudes towards wild edible mushrooms among the population in the region of Varna, as well as of the extent and manner of common mushroom usage depending on respondent sex, educational level and main residence. Based on the statistically significant correlations between a series of examined parameters, we could suggest the need of a wide ethnomycological study in our country on this topic. A thorough analysis of a number of foreign practices world-wide is used as a comparative study in our investigation. 


\section{REFERENCES:}

1. Ruiz-Almenara C, Gándara E, Gómez-Hernández M. Comparison of diversity and composition of macrofungal species between intensive mushroom harvesting and non-harvesting areas in Oaxaca, Mexico. Peer J. 2019 Dec 18;7:e8325. [PubMed]

2. Jabloñska-Rys E, Skrzypczak K, Slawinska A, Radzki W, Gustaw W. Lactic acid fermentation of edible mushrooms: tradition, technology, current state of research: a review. Compr Rev Food Sci Food Saf. 2019 May; 18(3):655-669. [Crossref]

3. Singhal S, Rasane P, Kaur S, Garba U, Singh J, Raj N, et al. Mushroom cultivation, processing and valueadded products: a patent based review. Recent Pat Food Nutr Agric. 2019; 10(1):3-19. [PubMed]

4. Svanberg I, Lindh H. Mushroom hunting and consumption in twentyfirst century post-industrial Sweden. $J$ Ethnobiol Ethnomed. 2019 Aug 19; 15(1):42. [PubMed]

5. Fontefrancesco MF, Pieroni A. Renegotiating situativity: transformations of local herbal knowledge in a Western Alpine valley during the past 40 years. J Ethnobiol Ethnomed. 2020 Oct 1;16(1):58. [PubMed]

6. Sitotaw R, Lulekal E, Abate D. Ethnomycological study of edible and medicinal mushrooms in Menge District, Asossa Zone, Benshangul Gumuz Region, Ethiopia. J Ethnobiol Ethnomed. 2020 Mar 4;16(1):11. [PubMed]

7. Molares S, Toledo CV, Stecher G, Barroetaveña C. Traditional mycological knowledge and processes of change in Mapuche communities from Patagonia, Argentina: A study on wild edible fungi in Nothofagaceae forests. Mycologia. 2020 Jan-Feb;112(1): 9-23. [PubMed]

8. Milenge Kamalebo H, Nshimba Seya Wa Malale H, Masumbuko
Ndabaga C, Degreef J, De Kesel A. Uses and importance of wild fungi: traditional knowledge from the Tshopo province in the Democratic Republic of the Congo. J Ethnobiol Ethnomed. 2018 Feb 12;14(1):13. [PubMed]

9. Raman J, Jang KY, Oh YL, Oh M, Im JH, Lakshmanan $\mathrm{H}$, et al. Cultivation and nutritional value of prominent Pleurotus spp.: an overview. Mycobiology. 2020 Nov 2;49(1):1-14. [PubMed]

10. Soro B, Koné NA, Vanié-Léabo LPL, Konaté S, Bakayoko A, Koné D. Phytogeographical and sociolinguistical patterns of the diversity, distribution, and uses of wild mushrooms in Cote d'Ivoire, West Africa. J Ethnobiol Ethnomed. 2019 Jan 18;15(1):5. [PubMed]

11. Mérida Ponce JP, Hernández Calderón MA, Comandini O, Rinaldi AC, Flores Arzú R. Ethnomycological knowledge among Kaqchikel, indigenous Maya people of Guatemalan Highlands. J Ethnobiol Ethnomed. 2019 Jul 17;15(1):36. [PubMed]

12. Wendiro D, Wacoo AP, Wise G. Identifying indigenous practices for cultivation of wild saprophytic mushrooms: responding to the need for sustainable utilization of natural resources. J Ethnobiol Ethnomed. 2019 Dec 12;15(1):64. [PubMed]

13. Farfan-Heredia B, Casas A, Rangel-Landa S. Cultural, economic, and ecological factors influencing management of wild plants and mushrooms interchanged in Purepecha markets of Mexico. J Ethnobiol Ethnomed. 2018 Nov 20;14(1):68. [PubMed]

14. Santiago FH, Moreno JP, Cazares BX, Suarez JJ, Trejo EO, de Oca GM, et al. Traditional knowledge and use of wild mushrooms by Mixtecs or Nuu savi, the people of the rain, from Southeastern Mexico. J Ethnobiol
Ethnomed. 2016 Sep 5;12(1):35. [PubMed]

15. Haro-Luna MX, Ruan-Soto F, Guzman-Davalos L. Traditional knowledge, uses, and perceptions of mushrooms among the Wixaritari and mestizos of Villa Guerrero, Jalisco, Mexico. IMA Fungus. 2019 Sep 16;10:16. [PubMed]

16. Quinónez-Martinez M, RuanSoto F, Aguilar-Moreno IE, GarzaOcanas F, Lebgue-Keleng T, LavinMurcio PA, et al. Knowledge and use of edible mushrooms in two municipalities of the Sierra Tarahumara, Chihuahua, Mexico. J Ethnobiol Ethnomed. 2014 Sep 17;10:67. [PubMed]

17. Kotowski MA, Pietras M, Luczaj L. Extreme levels of mycophilia documented in Mazovia, a region of Poland. J Ethnobiol Ethnomed. 2019 Feb 12;15(1):12. [PubMed]

18. Farfan-Heredia B, Casas A, Moreno-Calles AI, Garcia-Frapolli E, Castilleja A. Ethnoecology of the interchange of wild and weedy plants and mushrooms in Phurepecha markets of Mexico: economic motives of biotic resources management. $J$ Ethnobiol Ethnomed. 2018 Jan 15;14(1):5. [PubMed]

19. Stryamets N, Elbakidze M, Ceuterick M, Angelstam P, Axelsson R. From economic survival to recreation: contemporary uses of wild food and medicine in rural Sweden, Ukraine and NW Russia. J Ethnobiol Ethnomed. 2015 Jun 16;11:53. [PubMed]

20. Fongnzossie EF, Nyangono CFB, Biwole AB, Ebai PNB, Ndifongwa $\mathrm{NB}$, Motove J, et al. Wild edible plants and mushrooms of the Bamenda Highlands in Cameroon: ethnobotanical assessment and potentials for enhancing food security. J Ethnobiol Ethnomed. 2020 Mar 4;16(1):12. [PubMed]

Please cite this article as: Dimitrova T, Marinov P, Yaneva G, Ivanov D. Analysis of usage and quality of wild edible mushrooms by people from Bulgaria, compared to other foreign countries. J of IMAB. 2021 Oct-Dec;27(4):4151-4156.

DOI: https://doi.org/10.5272/jimab.2021274.4151

Received: 01/06/2021; Published online: 13/12/2021

\section{Address for correspondence:}

Tsonka Dimitrova, Department of Biology, Faculty of Pharmacy, Medical University, Varna, Bulgaria

E-mail: tsonka72@abv.bg 